\title{
QUANTIFYING SQUARE MEMBRANE WRINKLE BEHAVIOR USING MITC SHELL ELEMENTS
}

\author{
Mindy B. Jacobson ${ }^{\star}$, Takashi Iwasa ${ }^{\dagger}$, M.C.Natori ${ }^{\ddagger}$ \\ - NASA, Goddard Space Flight Center, Greenbelt, Maryland, USA \\ ${ }^{\dagger}$ University of Tokyo, Tokyo, Japan \\ ${ }^{\ddagger}$ Institute of Space and Astronautical Science, Sagamihara, Kanagawa, Japan
}

\begin{abstract}
$\underline{\text { Abstract }}$
For future membrane based structures, quantified predictions of membrane wrinkling behavior in terms of amplitude, angle and wavelength are needed to optimize the efficiency and integrity of such structures, as well as their associated control systems. For numerical analyses performed in the past, limitations on the accuracy of membrane distortion simulations have often been related to the assumptions made while using finite elements. Specifically, this work demonstrates that critical assumptions include: effects of gravity, supposed initial or boundary conditions, and the type of element used to model the membrane. In this work, a $0.2 \mathrm{~m}^{2}$ membrane is treated as a structural material with non-negligible bending stiffness. Mixed Interpolation of Tensorial Components (MITC) shell elements are used to simulate wrinkling behavior due to a constant applied in-plane shear load. Membrane thickness, gravity effects, and initial imperfections with respect to flatness were varied in numerous nonlinear analysis cases. Significant findings include notable variations in wrinkle modes for thickness in the range of $50 \mu \mathrm{m}$ to $1000 \mu \mathrm{m}$, which also depend on the presence of an applied gravity field. However, it is revealed that relationships between overall strain energy density for cases with differing initial conditions are independent of assumed initial conditions. In addition, analysis results indicate that the relationship between amplitude scale (W/t) and structural scale (L/t) is linear in the presence of a gravity field.
\end{abstract}

Keywords: wrinkle, simulation, finite elements, mixed interpolation of tensorial components (MITC), membrane structures

\section{$\underline{\text { Introduction }}$}

With the need to develop increasingly more efficient and lighter mechanical and structural systems for spacecraft, many researchers have for decades been experimenting with various types of polymer membranes and working to simulate their behavior., ${ }^{1,2}$ To date, the most detailed simulations have been limited to focusing on global distortion and the overall stress field; analysis tools have not been robust enough to quantify wrinkle features such as amplitude, wavelength and orientation angle. In the future, quantified predictions of membrane wrinkling behavior in terms of these three characteristics can be used to optimize the efficiency and integrity of membrane structures and associated control systems.

Prominent space-based examples of structural systems employing thin membrane materials include the Echo-1 passive communications satellite, high altitude balloons, Fresnel lens reflectors, and a sun shield for the James Webb Space Telescope (JWST), as illustrated in Figure 1 (a)-(d), respectively. Each of these structures is sensitive to wrinkle patterns in unique ways, significantly impacting the function of each.

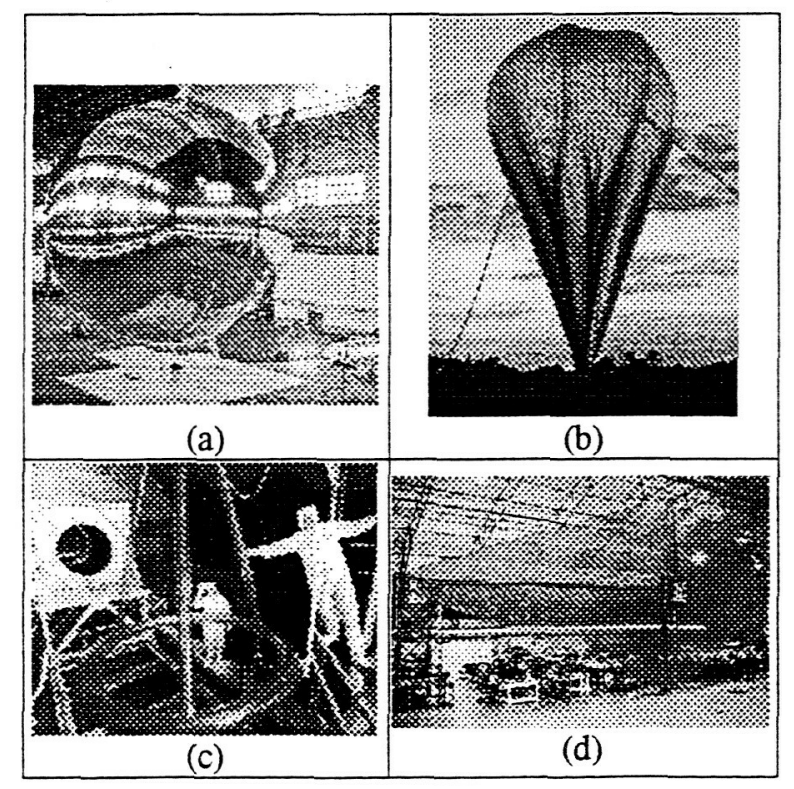

Fig. 1 Space-based membrane structures: (a) Echo1, (b) high altitude balloon, (c) Fresnel lens, (d) a proposed sun shield concept for JWST

For membrane surfaces designed to be specular, such as Echo-1 and the Icns, wrinkles cannot be tolerated. Wrinkles are an asset, however, to the high altitude balloon design. Wrinkle tolcrance lying somewhere in between these two extremes is given by 
the sun shield design. That is, wrinkles can be tolerated up until they might induce buckling in the inflated booms or up to the point that wrinkle amplitudes cause adjacent layers of membrane surfaces to come into contact.

The analytical study documented herein includes wrinkle simulations for the basic case of a square membrane fixed at each corner and subjected to inplane shear, which is a case that has not yet been treated in detail by previous works. Use of the Mixed Interpolation of Tensorial Components (MITC) shell element has enabled this detailed quantitative study for reasons discussed in the following section. The subsequent section describes numerous nonlinear analysis cases considered, in which membrane thickness, gravity effects, and initial imperfections with respect to flatness were varied. Simulation results are presented and quantified in terms of wrinkle amplitude, orientation and wavelength.

Results of this work are significant as a tool for: (1) assessing numerical analysis sensitivities in preparation for data correlation, and (2) developing alternative methods for analyzing membrane wrinkling behavior without relying on finite element methods. ${ }^{3}$

\section{Wrinkling Theory}

Although a complete history of the development of theories for explaining wrinkling behavior are beyond the scope of this paper, three theories traditionally used to study and simulate wrinkled membranes are briefly summarized here.

First, Tension Field Theory (TFT) mathematically describes wrinkling in terms of solid mechanics. ${ }^{4}$ It asserts that membranes can be described as structures of sufficiently little thickness such that they have zero bending stiffness. As a result, they have no capacity to support compressive load or carry compressive stress.

Plate Theory is assumed when considering structural responses that are dominated by in-plane structural stiffness. Out-of-plane, or transverse loads are considered negligible by comparison. Elements treated according to this theory are not expected to undergo significant amounts of bending, although they do have significant thickness.

Classic Shell Theory is assumed when a thin structural element is loaded both in-plane and out-ofplane, and bending is expected. The theory includes non-negligible bending stiffness and can be used for

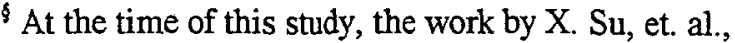
entitled "Wrinkling Analysis of a Kapton Square Membrane Under Tensile Loading" had not yet been pililished in the prinecels from the $44^{\text {th }}$

AIAA/ASME/ASCLE/AHS Structures, Structural

Dynamics and Materials Conference, 7-10 April, 2003. considering nonlinear deformation, or strain. Further, it considers that the shell is an inextensible surface and is modeled at the mid-plane of that surface - therefore, transverse stresses through the thickness of a surface are not captured.

For elastic materials, such as membranes considered in this work, inextensibility is a fundamental principle stating that the length of a distorted path cannot exceed the length of an undistorted path of the same structure. In other words, geometric compatibility between initial and final states must be preserved. For wrinkling phenomena, this principle relates to the transverse direction. Hence, neither Plate nor Classic Shell Theory is sufficient for fully characterizing wrinkling behavior on its own.

The Mixed Interpolation of Tensorial Components (MITC) shell element was developed by K. J. Bathe and E. N. Dvorkin to combine the plate and shell theories in finite element analyses. ${ }^{5,6,7}$ The stress and strain tensors at each element node are interpolated along each edge of the element, as well as through the element thickness. Thus, true strain energy density levels may be captured. This is critical, given that wrinkling is best described as the minimum energy response for accommodating in-plane strain while also satisfying the inextensibility principle in the transverse direction.

Mathematically, wrinkles have been described in terms of both TFT and shell theory. For the purposes of this study, to be consistent with MITC element formulation, the principles of shell theory are used to characterize wrinkle states, as described in the following table.

Table 1. Shell Theory Wrinkle State Criteria

\begin{tabular}{cl}
\hline Taut & $\sigma_{11}>0$ and $\sigma_{22}>0$ \\
Wrinkled & $\sigma_{11}>0$ and $\sigma_{22} \leq 0$ \\
Slack & $\sigma_{11} \leq 0$ and $\sigma_{22} \leq 0$ \\
\hline
\end{tabular}

\section{Analysis}

Method

The computational tool used to perform these simulations is a Finite Element Analysis Program: Personal Version (FEAPpv) ${ }^{8,9,10}$ The 4-node MITC shell element was added by authors to the element library. The Newton and modified Newton methods are used to compute nonlinear analysis solutions.

Model

The $0.2 \mathrm{~m}^{2}$ membrane finite element model is shown in Figure 2. The mesh was discritized willi regard to optimal aspect ratio for best performance of 
the 4-node MITC shell element. ${ }^{11}$ Computation time is of secondary importance in this study; the model consists of 10000 elements $\left(0.002 \mathrm{~m}^{2}\right.$ each $)$ and 10201 nodes.

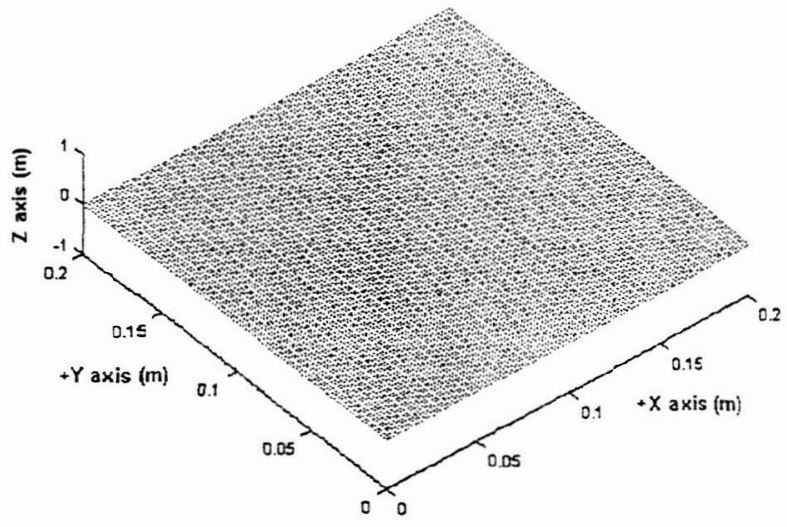

Fig. 2 Finite Element Model

The membrane is constrained at 3 of 4 corners in ail degrees of freedom except out of piane rotation. At the fourth corner of the membrane, a small displacement is applied in the direction of the $+X$ axis $(\delta \mathrm{x}=0.001 \mathrm{~m})$ and constraints are applied against translation in the $Y$ and $Z$ directions, as well as against rotation about the $X$ and $Y$ axes.

The magnitude of applied displacement was set with consideration for the assumption that this analytical study is based on linear elastic behavior of the membrane. Resultant stress levels are not to exceed the $5 \%$ yield point for $\mathrm{H}$-type Kapton; refer to Table 2 for assumed material properties.

Table 2. H-type Kapton Material Properties

\begin{tabular}{ccc}
\hline Property & Value & Unit \\
\hline Tensile Strength, Ultimate & 243.04 & $\mathrm{MPa}$ \\
Yield Point (3\% offset) & 95.06 & $\mathrm{MPa}$ \\
Yield Point (5\% offset) & 123.48 & $\mathrm{MPa}$ \\
Elongation, Ultimate & 80 & $\%$ \\
Young's Modulus, E & 2959.6 & $\mathrm{MPa}$ \\
Poisson's Ratio, v & 0.34 & \\
Density, $\rho$ & 1.42 & $\mathrm{~g} / \mathrm{cm}^{3}$ \\
\hline
\end{tabular}

\section{Cases}

Parameters discussed in the previous section are held constant for all numerical simulations. Each analysis case performed in this study was derived based on the need to systematically evaluate effects of additional analytical variables. Table 3 lists the variable parameters treated.
Table 3. Parameters Varied for Analytical Study

\begin{tabular}{ccc}
\hline Parameter & Values & Units \\
\hline Thickness, $\mathrm{t}$ & $50,125,150,175$, & $\mu \mathrm{m}$ \\
Gravity & $300,500,1000$ & $\mathrm{M}-\mathrm{N}$ \\
$\begin{array}{c}\text { Initial Flatness }(\rho \cdot \mathrm{A} \cdot \mathrm{t}) \cdot \mathrm{G} \\
\text { Imperfection }\end{array}$ & $-10 \% \mathrm{t} \leq \mathrm{NRN} \leq+10 \% \mathrm{t}$ & $\mu \mathrm{m}$ \\
\hline
\end{tabular}

For each thickness, geometrically nonlinear analyses were performed in order to assess the wrinkling behavior both with and without the gravity effect, which is assumed perpendicular to the plane of the membrane. For the cases including this effect, membrane sag due to gravity is taken to be the initial distorted shape prior to applying the shear load (as an enforced displacement, $\delta \mathrm{x}=0.001 \mathrm{~m}$ ).

For cases not including the gravity effect, the initial flatness of the membrane is assumed to not be perfect. That is, in reality, no square membrane surface can be considered perfectly flat when it is suspended at each of its 4 corners. In this study, the initial deformed shape (or, flatness imperfection) is determined in one of two ways. The first method is to apply random values of out-of-plane distortion at each node. These values are $\pm 10 \%$ of the membrane thickness and are taken from a normal random number (NRN) generator, and they are applied as initial conditions. Alternatively, the initial deformation is assumed to correspond to the sag shape due to gravity, but applied as a geometric initial condition, rather than taken as the result of an applied load.

Table 4 summarizes each of the analysis cases considered in this study. All cases, but the first ("SelfWeight"), are considered to be wrinkling analysis cases for which a detailed study of the results has been conducted. The "Self-Weight" case is taken to be a baseline for comparing the quantified effects due to gravity simulated in the other three wrinkling cases. Note that each membrane thickness given in Table 3 is considered for all cases.

\section{$\underline{\text { Results }}$}

\section{Self-Weight Case}

The purpose of this case is to simulate the static effect of a (1G) gravity field on a square membrane heid fixed (5DOF) at all four corners. The gravity field is simulated by computing an effective gravity force $\left(F_{G}\right)$ for each membrane thickness, which is evenly distributed over the entire area (A) and applied discretely at each node.

Figure 3 illustrates the resultant deformed shane that is characteristic for each membrane lhickness, from

3

American Institute of Aeronautics and Astronautics 
Table 4. Description of Analysis Cases

\begin{tabular}{|c|c|c|c|c|}
\hline Case & $\begin{array}{l}\text { Applied } \\
\text { Load }\end{array}$ & Initial Condition & $\begin{array}{l}\text { Boundary } \\
\text { Condition }\end{array}$ & Illustration \\
\hline "Self-Weight" & $\begin{array}{c}\text { Effective } \\
\text { Gravity } \\
\text { Force at } \\
\text { Each Node }\end{array}$ & None & $\begin{array}{l}\text { 5DOF Constrained } \\
\text { at All } 4 \text { corners }\end{array}$ & \\
\hline "Gravity" & $\begin{array}{c}\delta \mathrm{x}=0.001 \mathrm{~m} \\
\text { at one } \\
\text { corner } \\
(\mathrm{X}=0.2 \mathrm{~m} \\
\mathrm{Y}=0.0 \mathrm{~m})\end{array}$ & $\begin{array}{l}\text { Restart of Self- } \\
\text { Weight Case }\end{array}$ & $\begin{array}{l}\text { 5DOF Constrained } \\
\text { at } 3 / 4 \text { corners; } \\
\text { 4DOF constrained } \\
\text { at corner of } \\
\text { applied load }\end{array}$ & \\
\hline $\begin{array}{l}\text { "No Gravity } \\
\text { NRN" }\end{array}$ & \multirow{2}{*}{$\begin{array}{c}\delta \mathrm{x}=0.001 \mathrm{~m} \\
\text { at one } \\
\text { corner } \\
(\mathrm{X}=0.2 \mathrm{~m} \\
\mathrm{Y}=0.0 \mathrm{~m})\end{array}$} & $\begin{array}{l}\text { Flatness } \\
\text { Imperfection due } \\
\text { to random } \\
\text { distribution of } \\
\text { distortions }(\delta z)\end{array}$ & \multirow{2}{*}{$\begin{array}{l}\text { 5DOF Constrained } \\
\text { at } 3 / 4 \text { corners; } \\
\text { 4DOF constrained } \\
\text { at corner of } \\
\text { applied load }\end{array}$} & \\
\hline $\begin{array}{l}\text { "No Gravity } \\
\text { S-W" }\end{array}$ & & $\begin{array}{l}\text { Sag shape due to } \\
\text { Self-Weight } \\
\text { analysis }\end{array}$ & & \\
\hline
\end{tabular}

$50 \mu \mathrm{m}$ to $1000 \mu \mathrm{m}$. Note that the shape of any cross section profile is not a catenary.

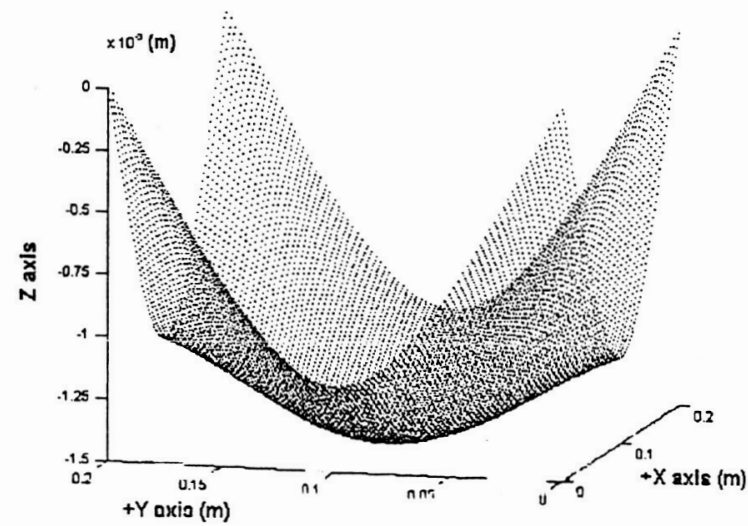

For comparison with the three wrinkling analysis cases, total strain energy density $(U)$ for each membrane thickness is presented in Figure 4; a nondimensional structural scale $(\mathrm{L} / \mathrm{t})$ parameter is given along the abscissa.

It is clear that $U$ rapidly decreases with thickness. The rate of decrease is related to the rate of decrease in membrane stiffness, which is a compound function of both $\mathrm{t}^{2}$ and $\mathrm{t}^{3}$ for in-plane and bending stiffness, respectively. Overall work required to distort the membrane is significantly less for small thickness than for large; therefore, this relationship is expected.

Fig. 3 Characteristic Deformation Due to Gravity 


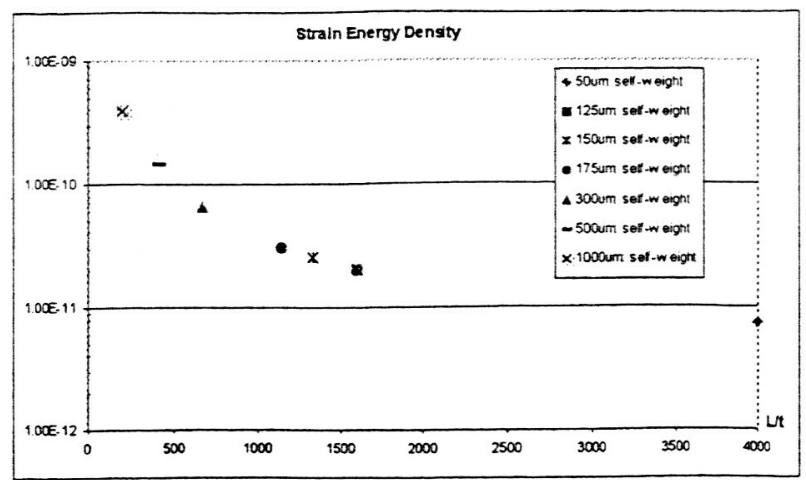

Fig. 4 Strain Energy Density Due to Gravity Sag

\section{Gravity Case}

The solution of this case is obtained from a nonlinear solution re-start of the "Self-Weight" case while applying the corner shear force. In this sense, the simulation may be considered to be the result of an initial applied load, or force. (This is contrary to the "No Gravity S-W" case, described below, in which the gravity effect is modeled as a geometric initial condition, or distortion.)

Although simulations for each thickness given in Table 3 were performed, for brevity only the deformed shapes for $\mathrm{t}=50,175,300$, and $1000 \mu \mathrm{m}$ are illustrated in Figure 5. Simulation results indicate that when $t<$ $500 \mu \mathrm{m}$, maximum out-of-plane distortions ( $\delta \mathrm{z}$, in either the $+Z$ or $-Z$ direction) decrease as thickness decreases. However, there is no clear trend for maximum stress levels that can be related to thickness; the difference between maximum and minimum values is only $5.7 \%$.

Element-by-element analysis of wrinkle state, as defined in Table 1, for each membrane thickness has revealed that for $\mathrm{t}>300 \mu \mathrm{m}$, wrinkle criteria based on major principal stresses does not accurately characterize membrane distortion because some regions do carry some level of compressive stress without buckling due to sufficiently high levels of bending stiffness. This may be confirmed by examining the deformation modes given in Figure 5; true wrinkling behavior (a result of localized buckling) is dominant only when $\mathrm{t} \leq 300 \mu \mathrm{m}$.

\section{No Gravity NRN Case}

This analysis case was prepared by enforcing, as a geometric initial condition, small out-of-plane $(\delta z)$ distortions at each node location. The magnitude of these distortions is not greater than $10 \%$ of the membrane thickness, and they were taken from a normal random number $(\mathrm{NRN})$ generator.

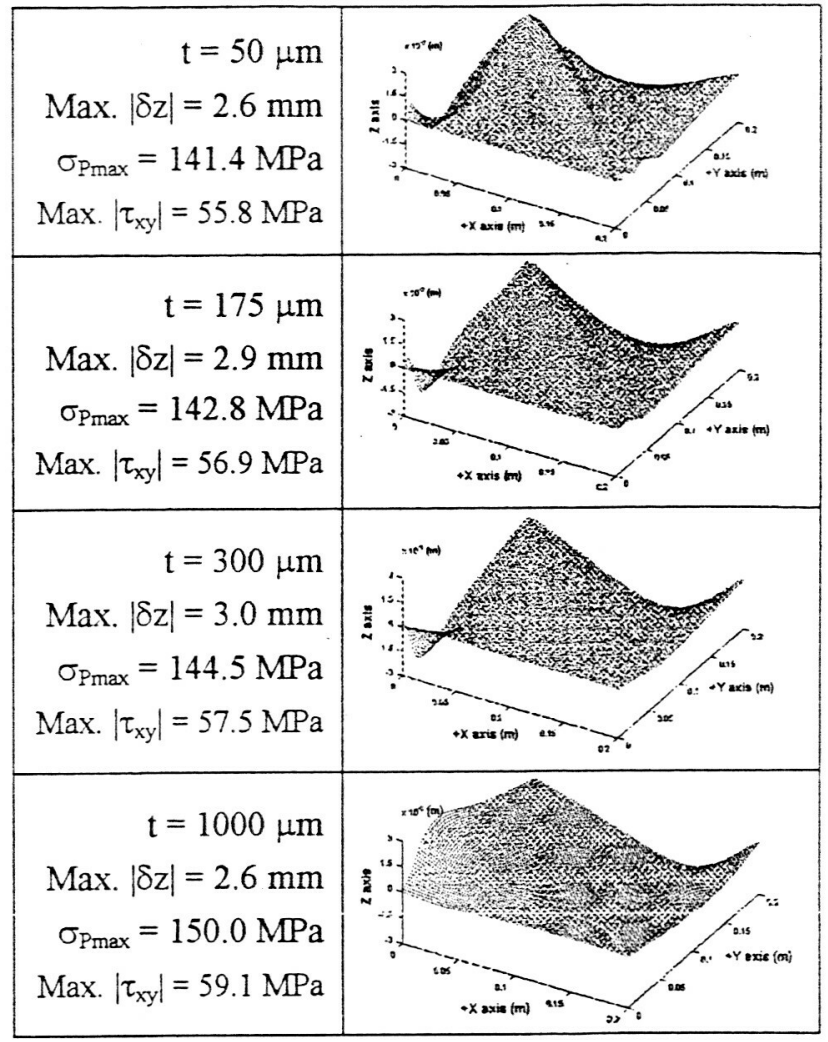
Fig. 5 Wrinkled Membranes Due to Applied Corner
Shear Load, Including Gravity Field

This initial condition was chosen in order to induce a perturbation in the flatness of the membrane - in the absence of a gravity effect. The perturbation is necessary because the assumption of a perfectly flat surface is an inherently stable system under static load conditions and, therefore, cannot be numerically induced to wrinkle.

Other analytical methods have enforced, as an initial condition for wrinkling simulations, the primary eigenmode of deformation for the given structure. However, this can arguably bias the solution in favor of deformation modes that correspond only to trajectories, or eigenvectors, related to that particular eigenmode.

As in Figure 5 for the Gravity case, Figure 6 illustrates wrinkled membranes only for $\mathrm{t}=50,175$, 300 , and $1000 \mu \mathrm{m}$. A quantitative comparison of the stresses and deformations associated with these results and those given in Figure 5 reveals no significant differences. However, there are obvious qualitative differences as thickness decreases. 


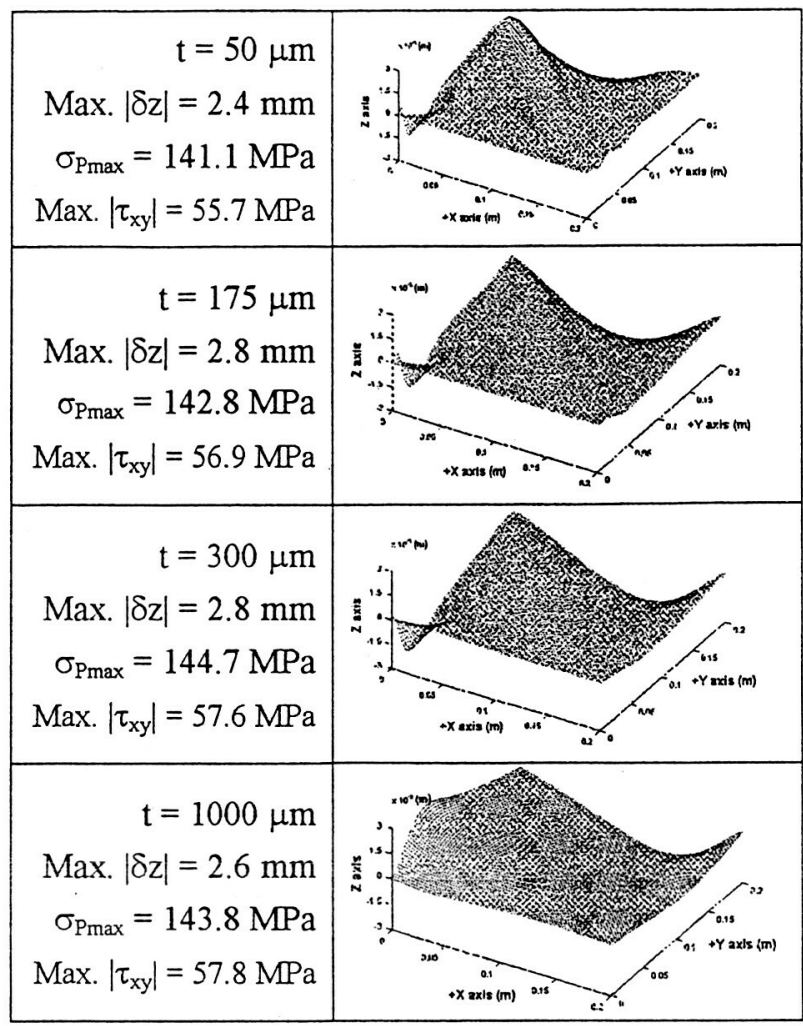

Fig. 6 Wrinkled Membranes Due to Applied Corner Shear Load, Including Gravity Field and Initial NRN Imperfection

Therefore, in order to truly characterize wrinkling behavior it is necessary to quantify wrinkle orientation in addition to amplitude. This has been done, for this study, in a rudimentary way by plotting maximum and minimum principle stresses at a constant cross section in the membrane, for each thickness as shown in Figure 7. The most significant detail to notice from this comparison is that minor principle stresses tend to reverse, and with greater frequency, as thickness decreases. This is the cause of increasingly numerous and skewed wrinkles when thickness is less than 300 $\mu \mathrm{m}$.

\section{No Gravity S-W Case}

This wrinkling case differs from those presented in the previous two sections in that the assumed initial condition is determined by the appropriate degree of gravity sag deformation, depending on thickness, that was computed in the Self-Weight case. This is unlike the Gravity analysis case because the initial condition is

'This topic is expanded and thoroughly treated in a separate study entitled "A Spectrum Evaluation Method for Wrinkled Membranes Using Two-Dimensional Fast Fouricr Transform" by T. Iwasa, ct. al. ${ }^{3}$

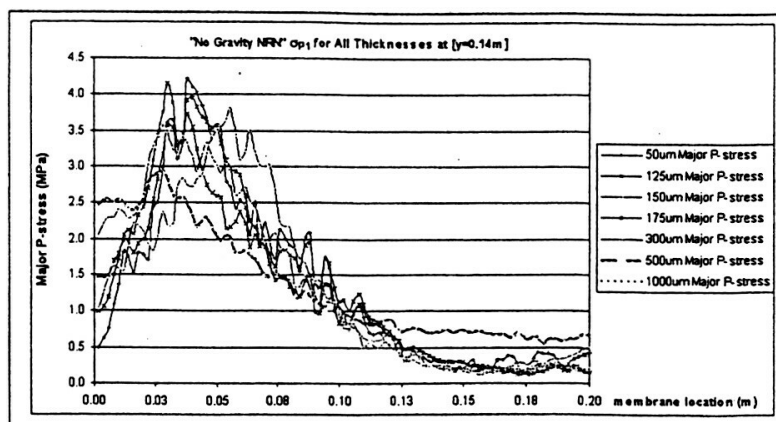

(a) Major Principle Stresses, $\sigma_{11}$

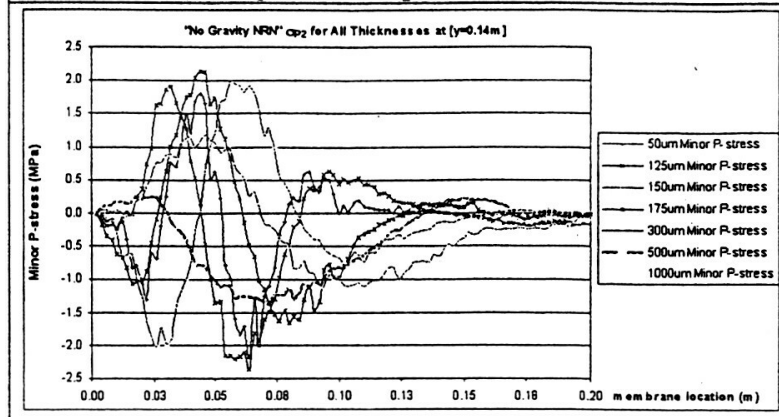

(b) Minor Principle Stresses, $\sigma_{22}$

Fig. $7 \sigma_{11}$ and $\sigma_{22}$ Along Membrane Cross Section: $\mathrm{Y}=\mathbf{0 . 1 4 m}$

applied as a geometric constraint, rather than as a distributed applied load $\left(\mathrm{F}_{\mathrm{G}}\right)$.

Figure 8 gives analysis results similar to those reported in Figures 5 and 6 , for $t=50,175,300$, and $1000 \mu \mathrm{m}$. These results reveal similar trends with respect to wrinkle state; when $\mathrm{t}>300 \mu \mathrm{m}$ deformation may not be accurately characterized by the term "wrinkled", according to the state definitions given in Table 1. In addition, stress levels and out-of-plane deformation are not significantly different than the other two wrinkling cases.

However, the deformed state when $\mathrm{t}=50 \mu \mathrm{m}$ is different than the previous two cases. In addition, differences are discovered when carefully analyzing membrane deformation at constant cross sections using the wrinkle scale parameter $(\mathrm{W} / \mathrm{t})$. This is discussed in greater detail in the following section.

\section{$\underline{\text { Discussion }}$}

In order to visualize how wrinkling behavior is effected by the different initial conditions it is beneficial to examine cross section plots at constant thickness for each analysis case. The non-dimensional wrinkle scale parameter $\mathrm{W} / \mathrm{t}$ is plotted versus structural scale $\mathrm{L} / \mathrm{t}$, where $\mathrm{W}=$ amplitude and $\mathrm{L}=$ edge length. For illustration, herc, the cross section plots for $\mathrm{t}=50$ ), 175 , 300 , and $1000 \mu \mathrm{m}$ at $\mathrm{y}=0.14 \mathrm{~m}$ arc shown in Figure 9 . 


$\mathrm{t}=50 \mu \mathrm{m}$
$\mathrm{Max} .|\delta \mathrm{z}|=2.7 \mathrm{~mm}$
$\sigma_{\mathrm{Pmax}}=138.5 \mathrm{MPa}$
$\mathrm{Max} \cdot\left|\tau_{x y}\right|=54.7 \mathrm{MPa}$
$\mathrm{t}=175 \mu \mathrm{m}$
$\mathrm{Max} \cdot|\delta \mathrm{z}|=2.5 \mathrm{~mm}$
$\sigma_{\mathrm{Pmax}}=142.9 \mathrm{MPa}$
$\mathrm{Max} \cdot\left|\tau_{x y}\right|=56.5 \mathrm{MPa}$

Fig. 8 Wrinkled Membranes Due to Applied Corner Shear Load, Including Gravity Field and Self-Weight Gravity Sag

A detailed examination of such plots for each membrane thickness reveals that deformation mode is independent of initial conditions when $\mathrm{t} \leq 150 \mu \mathrm{m}$. Also, for any thickness, the deformation modes for "Gravity" and "No Gravity S-W" are the same, but offset by the initial $\delta z$ offset due to the gravity sag shape. The disparity between these two deformation modes and that for the "No Gravity NRN" case becomes noticeable when $175 \mu \mathrm{m} \leq \mathrm{t}<1000 \mu \mathrm{m}$ and a phase shift between wrinkle peaks becomes apparent. But, when $t=$ $1000 \mu \mathrm{m}$, deformation mode is again independent of initial conditions. Another prominent trend to notice is that wavelength increases with thickness, regardless of assumed initial conditions.

Figure 10 illustrates the relationship between the wrinkle (W/t) and structural (L/t) scale parameters. It is important to note that this relationship is linear for the Gravity case. This indicates that analysis results may be scaled for correlation to ground-based experimental data - but only for square geometries. That is, previous research studying similar behavior but for a circular membrane has revealed that the same relationship is not linear. ${ }^{12}$ Rather, it increases nonlinearly towards a constant value as $\mathrm{L} / \mathrm{t}$ increases. So, the relationship helween wrinkle scale and struclural scale depends on geometry, not initial conditions.

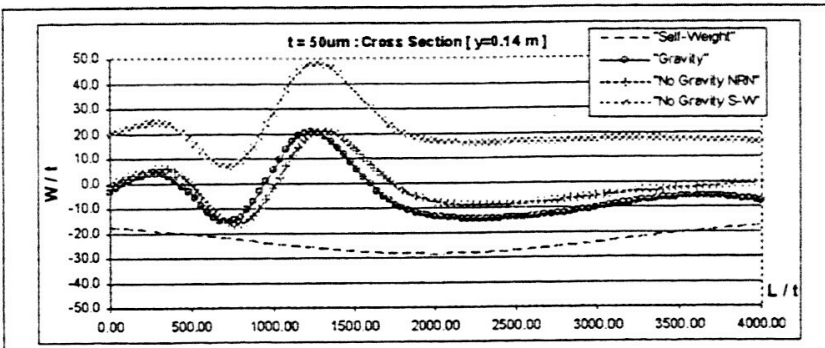

(a) $\mathrm{t}=50 \mu \mathrm{m}$

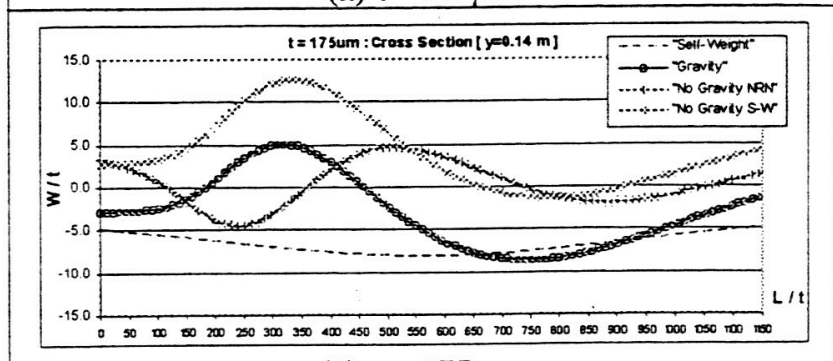

(b) $\mathbf{t}=175 \mu \mathrm{m}$

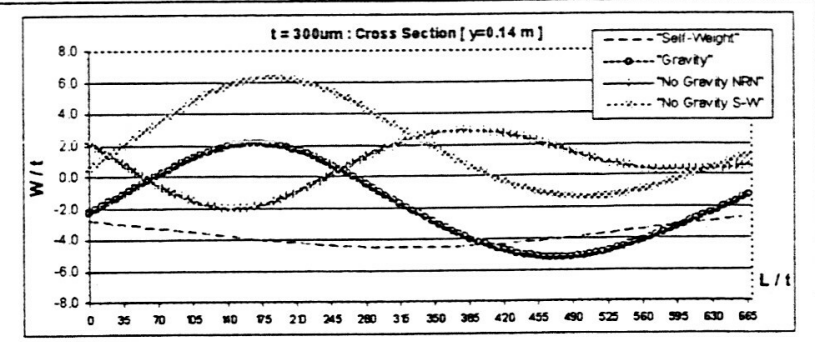

(c) $\mathrm{t}=\mathbf{3 0 0 \mu \mathrm { m }}$

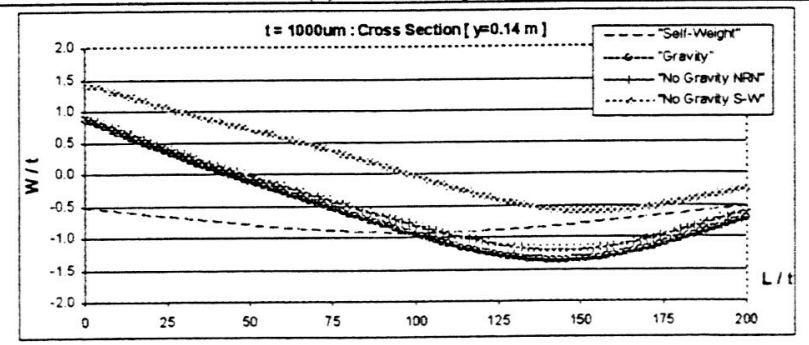

(d) $\mathbf{t}=1000 \mu \mathrm{m}$

Fig. $9(\mathrm{~W} / \mathrm{t})$ Along Membrane Cross Section: $Y=0.14 m$

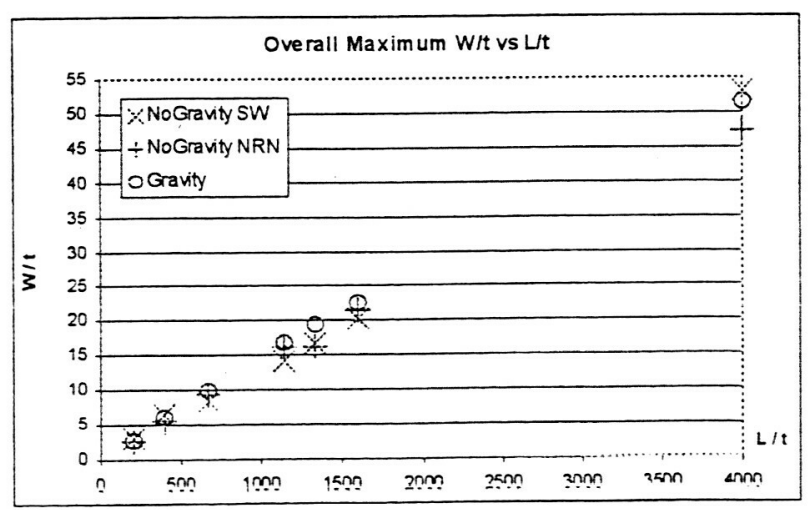

Fig. 10 Overall Maximum (W/t) versus (T/t) 
Plotting total strain energy density versus structural scale reveals the same relationship for all three wrinkling analysis cases as was revealed for the SelfWeight case. Refer to Figure 11, which shows that volumetric strain energy decreases rapidly with thickness and approaches a constant value. Therefore, the minimum energy response for accommodating inplane strain (in the form of wrinkles) approaches a constant as thickness becomes small. However, as previously noted, when $t \geq 500 \mu \mathrm{m}$ wrinkling is not an accurate description of the deformation due to in-plane shear.

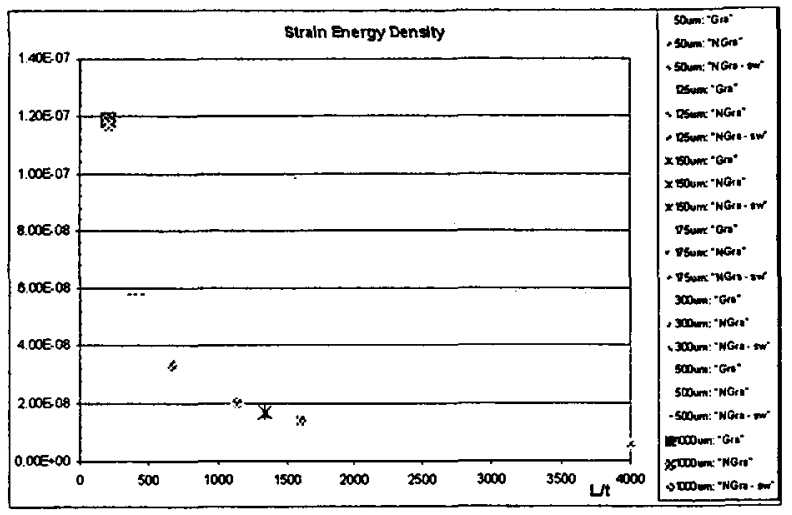

Fig. 11 Strain Energy Density versus (L/t) for All Wrinkling Cases

With respect to strain energy density, it is also interesting to note that the ratio of results for the Gravity and Self-Weight cases increases rapidly and approaches a constant value as thickness decreases (refer to Figure 12).

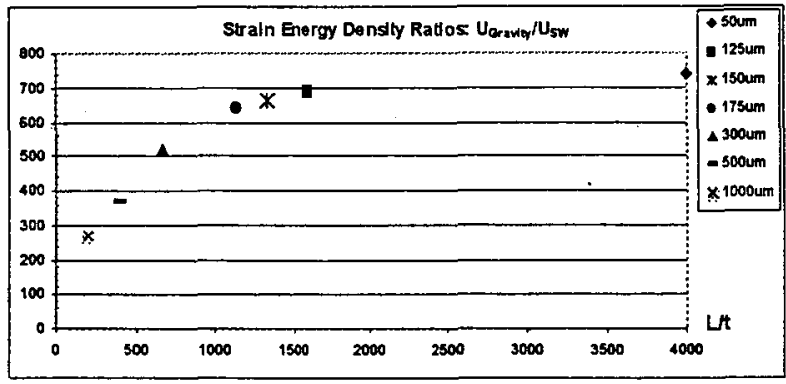

Fig. 12 Strain Energy Density Ratio:

$$
\mathbf{U}_{\text {Gravity }} / \mathbf{U}_{\text {Self-Weight }}
$$

Additional analyses have revealed that the ratio of strain energy density in the Gravity case to that for either of the other two wrinkling cases is $1.0 \pm 5 \%$, regardless of thickness. Therefore, initial conditions do not significantly impact the energy state of a wrinkled membrane. Other parameters relaung wrinkle amplitude to orientation are nesessary to fully quantify and qualify wrinkle behavior.

\section{Summary}

A systematic analytical study of the affects of thickness, gravity, and initial conditions on membrane wrinkling behavior has been presented. The universally applied static load in this study is in-plane shear, applied at one corner of a square membrane held fixed at the remaining three corners. This study is unlike others previously conducted on wrinkling behavior because of the geometry and numerical methods used to simulate behavior.

Detailed analysis of the simulation results for three different wrinkling cases reveal important relationships between deformation and thickness, as well as initial conditions:

- As thickness decreases, wrinkle behavior is increasingly sensitive to assumed initial conditions.

- As thickness increases, greater than $300 \mu \mathrm{m}$, membrane deformation may no longer be mathematically characterized as wrinkling.

- Overall stress and strain levels are not significantly effected by assumed initial conditions, though wrinkle orientation is.

- Though the magnitude of out-of-plane distortion is nearly constant regardless of thickness or initial condition, wrinkle wavelength increases with thickness for any assumed initial condition.

- By plotting wrinkle scale with respect to structural scale, it is shown that wrinkle scale is independent of the nonlinear relationship between thickness and stiffness.

- The relationship between wrinkle scale and structural scale is linear for the Gravity case in this study, though it is nonlinear for a circular membrane subjected to in-plane torsion. Therefore, this relationship depends on geometry, not initial conditions.

- The ratio of overall strain energy density in the Gravity case to that for either of the other two wrinkling cases is approximately 1.0 .

All of these results may be useful for correlating test data from a ground-based experiment. In addition, they reveal the fact that quantifying wrinkle behavior due to in-plane shear is a laborious and time-consuming task when utilizing finite element simulations. Because knowledge of precise wrinkle characteristics such as orientation and wavelength may be necessary for optical applications of membrane structures, this analytical study may bc uscful, as the background, for develnping alternative wrinkling analysis tonls capable of predicting such details uutright. 


\section{References}

${ }^{1}$ Stein, M. and Hedgepeth, J.M. "Analysis of Partly Wrinkled Membranes." NASA Technical Note. NASATN-D813, 1961.

${ }^{2}$ Mikulas, M. M. Jr. "Behavior of a Flat Stretched Membrane Wrinkled By the Rotation of an Attached Hub." NASA Technical Note. NASA-TN-D-2456, 1964.

${ }^{3}$ Iwasa, T., Jacobson, M., Natori, M.C., "A Spectrum Evaluation Method for Wrinkled Membranes Using Two-Dimensional Fast Fourier Transform", $5^{\text {th }}$ ALAA Gossamer Spacecraft Forum, GSF-8 presentation, 19-22 April 2004.

${ }^{4}$ Reissner, E., "On Tension Field Theory," Proc. VInt. Cong. Appl. Mech. (1938):88-92.

5 Bathe, K.J. and Dvorkin, E.N. "Short Communication: A Four-node Plate Bending Element Based on Mindlin/Reissner Plate Theory and A Mixed Interpolation." Int. J Num. Meth. Engr. 21 (1985): $367-$ 383.

${ }^{6}$ Bathe, K.J. and Dvorkin, E.N. "A Formulation of General Shell Elements - The Use of Mixed Interpolation of Tensorial Components." Int. J Num. Meth. Engr. 22 (1986): 697-722.

7 Bathe, K.J., Brezzi, F., and Fortin, M. "Mixedinterpolation Elements for Reissner-Mindlin Plates." Int. J Num: Meth. Engr 28 (1989): 1787-1801.

${ }^{8}$ Taylor, R.L. FEAP - A Finite Element Analysis Program Version 7.4 Programmer Manual. Berkeley: University of California Press, 2001.

${ }^{9}$ Taylor, RL. FEAPpv - A Finite Element Analysis Program, Personal Version 1.0 User Manual. Berkeley: University of California Press, 2001.

${ }^{10}$ Taylor, R.L. FEAP - A Finite Element Analysis Program Version 7.4 Theory Manual. Berkeley: University of California Press, 2002.

${ }^{11}$ Chapelle, D. and Bathe, K.J. "Fundamental Considerations for the Finite Element Analysis of Shell Structures." Computers \& Structures 66.1 (1998): 1936.

12 Iwasa, T., Natori, M.C., Noguchi, H. and Higuchi, K."Geometrically Nonlinear Analysis on Wrinkling Phenomena of a Circular Membrane." Research Report on Membrane Structures 16 (2002): 714. (in Japanese)

${ }^{13}$ Bucalem, M.L. and Bathe, K.J. "Higher-order MTC General Shell Elements." International Journal for Numerical Methods in Engineering 36 (1993): 3729-3754.

${ }^{14}$ Cerda, E., Ravi-Chandar, K., Mahadevan, L. "Thin Films: Wrinkling of An Elastic Sheet Under Tension." Bricr Communications in Nature 419 (2002): $57 \dot{y}-5 \bar{x}$.

15 Jwasa, T., Natori, M.C., and Higuchi, $K$. "Comparative Study on Bifurcation Theory and
Tension Field Theory for Wrinkling Analysis." Journal of Structural Engineering 49B (2003): 319-326. (in Japanese)

${ }^{16}$ Johnston, J. D. "Finite Element Analysis of Wrinkled Membrane Structures for Sunshield Applications." 43rd AIAA/ASME/ASCE/AHS/ASC Structures, Structural Dynamics and Materials Conference AIAA-2002-1456 (2002).

${ }^{17}$ Johnston, J. D., Blandino, J., Black, J., Pappa, R. "Structural Analysis and Testing of a Subscale Sunshield Membrane Layer." 44th ALAA/ASME/ASCE/AHS/ASC Structures, Structural Dynamics and Materials Conference AIAA-2003-1742 (2003).

${ }^{18}$ Miyamura, T. "Wrinkling on Stretched Circular Membrane Under In-plane Torsion: Bifurcation Analyses and Experiments." Engineering Structures 23 (2000): 1407-1425.

${ }^{19}$ Nakoshino, K. "Efficient Modification Scheme of Stress-Strain Tensor for Finite Element Analysis of Wrinkled Membranes." 44th AIAA/ASME/ASCE/AHS/ASC Structures, Structural Dymamics and Materials Conference AIAA=2003-1981 (2003).

${ }^{20}$ Wong, Y.W. and Pellegrino, S. "Computation of Wrinkle Amplitudes in Thin Membranes." 43rd ALAA/ASME/ASCE/AHS/ASC Structures, Structural Dynamics and Materials Conference AIAA-2002-1369 (2002)

${ }^{21} \mathrm{Su}, \mathrm{X}$., Abdi, F., Taleghani, B., and Blandino, J. "Wrinkling Analysis of a Kapton Square Membrane Under Tensile Loading." 44th ALAA/ASME/ASCE/AHS/ASC Structures, Structural Dynamics and Materials Conference AIAA-2003-1985 (2003). 